\title{
25 Research Square \\ Study on Sand Liquefaction Induced by Songyuan Earthquake with a Magnitude of M5.7 in China
}

Ping Li ( $\nabla$ chinaliping1981@126.com )

Key Laboratory of Earthquake Engineering and Engineering Vibration, Institute of Engineering Mechanics, China Earthquake Administration

\section{Zhaoyang Tian}

Shandong Earthquake Administration

\section{Jingshan Bo}

Hebei Key Laboratory of Earthquake Disaster Prevention and Risk Assessment

\section{Sheng Zhu}

Institute of Disaster Prevention

\section{Yuying li}

Institute of Disaster Prevention

\section{Research Article}

Keywords: Songyuan earthquake, sand liquefaction, field survey, cone penetration test, loess liquefaction

Posted Date: July 18th, 2021

DOI: https://doi.org/10.21203/rs.3.rs-653826/v1

License: (c) (i) This work is licensed under a Creative Commons Attribution 4.0 International License.

Read Full License 


\section{Abstract}

A large-scale sand liquefaction producing typical and novel surface phenomena was found at the epicenter of Songyuan M5.7 earthquake occurring on May 28, 2018. Field survey and experimental test encompassing boring sampling, standard penetration test(SPT), cone penetration test(CPT), scanning electron microscopy(SEM), X-ray diffraction(XRD), and X-ray fluorescence(XRF) were performed to ascertain the liquefaction damage and site characteristic. Cone penetration test is an excellent assay for the identification of liquefied sand layer and acquisition of physio-mechanical parameter. Moreover, the assay is applicable for on-site post-earthquake investigation. Factors promoting the formation and controlling the distribution of the sand liquefaction were analyzed. The liquefaction impacted an $80 \mathrm{~km} 2$ area, and was primarily embodied as sand boil and water sprout on rice field, despite producing no significant structural damage. Due to the simple profile of local soil layer, ground motion, geomorphic condition, and groundwater level were the main factors governing the distribution of the liquefaction. Majority of the liquefied sand layer was discovered at the depth less than $10 \mathrm{~m}$. However, deep layer liquefaction at the depth greater than $18 \mathrm{~m}$ was also discovered, which was demonstrated by the upward movement of liquefied sand towards the upper silty clay layer at the depth of $17 \mathrm{~m}$. Most importantly, we have identified loess liquefaction, a phenomenon which had not been reported previously in Northeast China. Lastly, it is important to highlight the risk of significant liquefaction damage at Songyuan. Hence, investigating the liquefaction risk is potentially beneficial for augmenting planning on earthquake mitigation, engineering reconnaissance, and design project.

\section{Introduction}

Liquefaction is a highly-destructive geological disaster induced by earthquake. History has recorded several liquefaction damage promoted by earthquake, such as the liquefaction damage in Niigata (Japan, 1964), Dagupan City (the Philippines, 1990), Chi-Chi (Taiwan, 1999), Kocaeli (Turkey, 1999), and Wenchuan (China, 2008). The destructive impact of liquefaction such as landslide promotes the collapse of buildings and thus the failure to achieve the targeted structural service life. Thus, ongoing study has been expanding our understanding on liquefaction, encompassing liquefaction mechanism, evaluation, and mitigation [1-7].

Post-earthquake investigation is an essential research methodology to study the distribution of liquefaction and identify the influencing factors of a liquefaction. There are two main objectives of the investigation: Initially, liquefied and non-liquefied region are determined based on ground damage. Successively, ground motion data are collected and quantitative data for detailed calculation and analysis are obtained by conducting drilling, screening test, standard penetration test, cone penetration test, and wave velocity test. Researchers and earthquake engineers deduce detailed information on the damage due to liquefaction and its related seismic activity by investigating liquefaction macrophenomena.Nevertheless, there are several limitations to previous investigation on liquefied macrophenomena: 1) While liquefied sites were identified during preliminary post-earthquake investigation by the observed surface macrophenomena such as sand boil, deep soil liquefaction with no 
obvious macrophenomena was frequently neglected. 2) Report on in-situ rare soil liquefaction in Northeast China, such as liquefaction of loess, is scarce. An earthquake with a magnitude of M5.7 occurred at Songyuan City, Jilin Province, China on 28th May, 2018. The earthquake was felt throughout Jilin Province, part of Heilongjiang Province, and Inner mongolia autonomous region. The epicenter of the earthquake was the Yamutu village, which is located at the alluvial terrace of Songhua River. The subsurface soil layer is mainly composed of fine sand and the water level is shallow. Thus, the occurrence of earthquake-induced liquefaction is increasing in recent years. In order to investigate the liquefaction distribution and damage, field survey and subsequent experimental test were conducted, involving boring sampling, standard penetration test (SPT), cone penetration test (CPT), scanning electron microscopy (SEM), X-ray diffraction (XRD), and X-ray Fluorescence (XRF). This paper initially provides an overview on the seismic characteristic of Songyuan and preliminary data on the characteristic of M5.7 earthquake. The earthquake history and current ground motion at Songyuan are elaborated. Thereafter, observed phenomena at liquefied and non-liquefied sites are presented. Not only typical liquefaction damages such as sand boil and waterspout were found, interesting novel phenomena such as deep soil liquefaction and rare soil liquefaction (i.e. loess liquefaction) were also indicated. Hence, the outcome of experimental series performed to ascertain the novel finding in Northeast China is discussed. Overall, this paper provides a better understanding on the prevention of liquefaction at Songyuan and fundamental understanding for future research.

\section{Seismic Characteristic Of Songyuan 2.1 Historical record of earthquake}

Songyuan is a city located at the Southern Songliao Basin. It has a complex fault structure and is one of the two cities in Northeast China which is fortified against seismic intensity of VIII. Series of earthquake with the magnitude of $M>5.0$ have occurred throughout the city's history. As mentioned in Dajin chorography, a destructive earthquake (Qianguo earthquake) with an estimated magnitude of (insert magnitude here) occurred on February 1119, and is documented as the most devastating earthquake attacking the city. Figure 1 illustrates the isoseismal map of the earthquake. The epicentral intensity was estimated between VIII and IX. Thousands of people died of the generated subsidence, accounting for approximately one-tenth of the combined population of Zhaozhou and Longzhou. The earthquake impacted the surrounding region of Songhua River Basin where Holocene sand layer is abundantly distributed. The shallow sand layer is saturated and loose, thus being susceptible to liquefaction under an earthquake. Despite the regional geomorphic feature, there was no large-scale landslide, ground crack, or other subsidence-related phenomena in the area. It is suggested that the large-scale subsidence was induced by sand liquefaction spanning from Tahu Town to Nongan Town.

In recent years, seismic activity with a magnitude of M4.0-5.0, particularly multiple earthquake swarm, frequently occurs around Songyuan [9]. Several earthquake have happened since 2006, comprising of: 1) Qianan earthquake with a magnitude of M5.0 on 31st March 2006, 2) Qianguo earthquake swarm with a magnitude of $M>5.0$ on 2013,3) Ningjiang earthquake with a magnitude of M4.9 on 23rd July 2017, and 
4) Songyuan earthquake with a magnitude of M5.7 on 28th May 2018. It is important to emphasize that the Qianguo earthquake swarm occurred repeatedly with varying intensity, beginning with a magnitude of $M>5.0$ on 31st October 2013 and ended with a magnitude of M5.5 at the end of 2014. During the time period, five earthquake with the magnitude of M5.0-5.9 and seven earthquake with the magnitude ofM4.04.9 hit the region. The multiple earthquake affected tens of thousands, and caused damage to buildings and farmland [10]. Thus, it is necessary to highlight the severe liquefaction risk at the region around Songyuan, noting the widely distributed shallow sand layer and underground water.

\subsection{Preliminary data on the characteristic of M5.7 earthquake}

Focal mechanism solution (FMS) is an excellent tool to analyze the mainshock-aftershock wave forms recorded as seismographs during an earthquake. Focal mechanism solution of seismographs generated during the Songyuan M5.7 earthquake indicated that it was a strike-slip earthquake. It was suggested that Fuyu-Zhaodong fault was the seismogenic fault. Figure 2 is the seismic intensity distribution map from seismic intensity survey. The highest intensity was VII, covering a $157 \mathrm{~km}^{2}$ area. The long axis of the region experiencing the intensity of VII was distributed along the northeast direction as long as $9.2 \mathrm{~km}$, whilst the short axis was $4.8 \mathrm{~km}$-long. On the other hand, the region experiencing an intensity of $\mathrm{VI}$ spanned an $880 \mathrm{~km}^{2}$ area. The long axis was $24 \mathrm{~km}$-long and the short axis was $16 \mathrm{~km}$-long. The intensity distribution was north-south asymmetry, and the decay rate of intensity was greater towards the southwest than the northeast.

The FMS analysis was supplemented by strong motion record. Figure 2 illustrates the strong motion record with peak ground acceleration (PGA) over $100 \mathrm{~cm} / \mathrm{s}^{2}$, documented at Daliba and Fenghua station by China Strong Motion Network Centre. The two stations were located at close proximity to the epicenter. Daliba station is located $16 \mathrm{~km}$ away from the epicenter, and recorded horizontal and vertical PGA of 159 and $189 \mathrm{~cm} / \mathrm{s}^{2}$ respectively. On the other hand, Fenghua station is located $24 \mathrm{~km}$ away from the epicenter, and recorded horizontal and vertical PGA of 189 and $48 \mathrm{~cm} / \mathrm{s}^{2}$.

\section{Field Investigation And Liquefaction Macro Phenomenon 3.1 Distribution of liquefaction}

Field survey identified that large-scale liquefaction was observed at the region affected by the earthquake with a seismic intensity of VII. In addition, few liquefaction sites were found at the region which experienced the seismic intensity of VI. Figure 3 illustrates the distribution of the liquefied sites. All of the liquefied sites were located at the countryside, of which sand boil and water spout were the primary liquefaction macrophenomena. Majority of the liquefaction was identified on rice field and a small proportion of the liquefaction caused damage to buildings. Approximately two hundred liquefied sites were detected, most of which were distributed across the left bank of Songhua River. On the other hand, only one liquefied site was observed at the right bank. The liquefaction zone covered approximately $9 \mathrm{~km}$ 
in both width and length and ( $80 \mathrm{~km}^{2}$ area) with Yamutu Village at Ningjiang District as the center. The liquefaction zone spanned from Songhua river on the east to Langjia Village (Qianguo County) on the west, and Guojia Village (Qianguo County) on the north to Jiangjia Village (Ningjia District) on the south.

\subsection{Observation on liquefaction macrophenomena}

Sand boil and waterspout were the main liquefaction macrophenomena discovered on liquefied sites. Majority of the macrophenomena was observed on rice field, and lesser proportion was found in forest, dry farmland and residential area. The liquefied sites discovered on rice field were the most severe among the discovered liquefied sites. The sites were characterized by long duration of liquefaction, deep liquefied hole, and large-scale eructation. Observed waterspout lasted from several minutes to several hours and irrigation water was still visible on a rice field at Jiangjia Village after four days of the earthquake, indicating that pressure of pore water in underground soil layer had not been fully dissipated Liquefied ejecta accumulated and were embodied as concentric (Fig. 4a) and string beads (Fig. 4b) shape. The diameter of most concentric shape was greater than $1 \mathrm{~m}$ and the largest recorded diameter was $10 \mathrm{~m}$. The volume of the ejecta was approximately $10 \mathrm{~m}^{3}$. On the other hand, the string beads shape was embodied as a combination of multiple concentric shape, with the maximum length exceeded $20 \mathrm{~m}$. The diameter of liquefied hole ranged from $20 \mathrm{~cm}$ to $4 \mathrm{~m}$, with the maximum depth of $4 \mathrm{~m}$.

Despite the appearance of liquefaction macrophenomena, there was no extensive damage to building caused by the liquefaction. There were only two observed occasion on liquefaction-related damage to building: the damage to a village committee office at Jiangjia (Fig. $5 a$ and $b$ ) and the damage to a house in Cuijia (Fig. $5 \mathrm{c}$ and d). These buildings are one-story masonry structures and liquefied sand (fine yellow sand and/or fine gray sand) were observed at both buildings Liquefied sand was exuded from the joint of $30 \mathrm{~m} \times 40 \mathrm{~m}$ concrete floor of the village committee office at Jiangjia. Similarly, liquefied sand was expelled from the corner of the office's foundation, despite producing only a slight damage to the building. The damage to the house in Cuijia was more pronounced than the damage to the village committee office at Jiangjia. The interior floor was fully covered by liquefied sand. Due to the absence of ring beam and construction column in the structure, liquefaction induced settlement and wall crack.

\subsection{Geotechnical property of earthquake sites}

Based on the finding of field survey elaborated in Sect. 3.1 and 3.2, drilling was carried out at the epicenter of the earthquake to the typical depth of soil to obtain data on soil layer as well as physical and mechanical index of the soil at liquefied and non-liquefied sites. Additionally, standard penetration test (SPT) and cone penetration test (CPT) were conducted to obtain valuable data for enriching previously reported liquefaction estimation method [11-15].

Figure 6 illustrates the sites at which drilling and CPT were performed. The sites were located at the region affected by the seismic intensity of VII. Drilling was performed at six sites, consisting of three sites at which sand eruption was identified and three sites at which sand eruption was not identified. Each drill hole reached the depth of approximately $20 \mathrm{~m}$. Samples of soil layer were collected and subjected to 
standard penetration test on the other hand, CPT was performed at thirteen sites, of which sand eruption was identified at four of the sites. At six out of the thirteen sites, both drilling and CPT were carried out.

The CPT employed a JMS-15A-3 probe with the cone bottom of $43.7 \mathrm{~mm}$, cone tip area of $15 \mathrm{~cm}^{2}$, friction cylinder surface area of $300 \mathrm{~cm}^{2}$, and the cone angle of $60^{\circ}$. The weight of CPT truck was 20 ton. Researchers have been extensively investigating the application of CPT for studying liquefaction, and have obtained satisfactory result from field application [13-15]. Based on SPT and CPT data, liquefied soil layer was identified by the cone tip resistance and lateral friction resistance value collected at liquefied sites. While non-liquefied soil layer was characterized by high cone tip resistance and low lateral friction resistance, liquefied soil layer was identified by low cone tip resistance and low lateral friction resistance.

Example of finding derived from the analysis of soil collected from a liquefied site, at which sand eruption was observed is presented in Fig. 7. The sampling site was located next to a rice field fully covered with water. Figure 7a indicates a simple profile of analyzed soil. The soil at the depth between $0 \mathrm{~m}$ and $2.5 \mathrm{~m}$ was composed of a layer of clay confining bed enriched with humus from plant root. Underground water was found at the $2.5 \mathrm{~m}$ depth. Successively, soil layer at the depth between $2.5 \mathrm{~m}$ and $20 \mathrm{~m}$ was filled with saturated fine yellowish-brown sand, medium gray sand, and fine gray sand successively. The soil layer at the depth greater than $20 \mathrm{~m}$ was constituted by a layer of clay confining bed. SPT and CPT data presented in Fig. 7b and c corresponded to the soil profile presented in Fig. 7a. Figure 7b and c show a clear distinction of each soil layer, as depicted by the value of cone tip resistance, lateral friction resistance, and friction ratio. More importantly, the SPT and CPT data clearly demonstrate the presence of a liquefied layer at the depth between $3 \mathrm{~m}$ and $4 \mathrm{~m}$. Overall, the finding presented in Fig. 7 supports the reliability of CPT to distinguish liquefied soil layer from the non-liquefied counterpart.

Figure 8 presents the example of finding derived from the analysis of soil collected from a non-liquefied site located next to a dry farmland. Underground water was discovered at a depth of $5 \mathrm{~m}$, deeper than the depth of which underground water was discovered at the liquefied site. Nonetheless, the top layer of the soil had a similar composition to the top layer of soil collected from liquefied site: a clay layer enriched humus from plant root, which spanned from $0 \mathrm{~m}$ to $0.5 \mathrm{~m}$ depth. Successively, the soil layer was filled with yellow and gray sand of medium and/or high fineness until the depth of $17.0 \mathrm{~m}$, at which grayishblack silty clay layer was detected. Underneath the silty clay layer, a layer of fine yellow and gray sand was detected. Visual inspection upon drilling demonstrated a slight liquefaction of the fine yellow sand layer at the 6-7 $\mathrm{m}$ depth, which agreed to the SPT and CPT data presented in Fig. 8b and c. More interestingly, deep liquefaction was observed. Liquefaction at lower sand layer generated an upward movement of liquefied sand towards the clay layer at the $17 \mathrm{~m}$ depth, as visually demonstrated by the drilled sample (Fig. 8d). The occurrence of the deep sand liquefaction was further ascertained by the low value of cone tip resistance and lateral friction resistance at the depth between $18 \mathrm{~m}$ and $19 \mathrm{~m}$ (Fig. 8b).

\section{Macrophenomena Of Rare Soil Liquefaction}




\subsection{Visual appearance}

Rare soil liquefaction was located at Wangjia Village (Fig. 9). The liquefied soil resembled silty clay and was constituted of grayish-black particle. The diameter of the ejecta was approximately $6 \mathrm{~m}$ and the thickness was approximately $15 \mathrm{~cm}$. The soil was soft yet viscous, and rollable into clay strip. In order to determine the type of the liquefied soil, micromorphology and chemical composition of the soil were analyzed by scanning electron microscopy (SEM), X-ray diffraction (XRD), and X-ray fluorescence (XRF).

\subsection{Micromorphology and composition analysis}

Micromorphological characterization of rare liquefied soil collected from ground surface was performed with Hitachi SU8020 field emission scanning electron microscope (accelerating voltage $=3 \mathrm{kV}$ ), and is presented in Fig. 10. As suggested in Fig. 10, the liquefied soil was composed of not only round sand particle but also flat clay particle, with the flat clay particle being more abundant than the round particle counterpart. Moreover, the primary structure of the soil was damaged, and small and medium pores constituted a greater proportion than did the large pore. Furthermore, the particle was contacted by (basal or contact) cementation. Based on the visual appearance (i.e. resemblance to silty clay) and elaborated micromorphological characteristic of the liquefied soil, it was postulated that the sample was liquefied loess. The hypothesis was supported by Bo et al who reported the distribution of sub-clay or loess layer in the investigated area, which was located at a shallow depth below the ground. Moreover, previous field and laboratory studies have reported the liquefaction of saturated loess under earthquake with the intensity of VI. The identity of liquefied soil was further verified through chemical composition analysis by XRD and XRF, presented in Fig. 11.

As demonstrated in Fig. 11, quartz was the major mineral of the liquefied soil (53.48\%), followed by albite (22.51\%), illite (15.26\%), orthoclase (5.52\%), and kaoline (3.23\%). On the other hand, $\mathrm{SiO}_{2}$ and $\mathrm{Al}_{2} \mathrm{O}_{3}$ were the most abundant elemental oxide, and oxygen was the major element of the soil. The major content of quartz in the liquefied soil was in agreement with the report by Wei [16] that quartz was a major mineral of Chinese loess. Thus, the mineral composition of liquefied soil was compared with the mineral composition of Malan loess reported by Liu et al. [insert citation], and is presented in Table 1. The $\mathrm{SiO}_{2}$ content of liquefied soil conformed with the reported $\mathrm{SiO}_{2}$ content of Malan loess, so did the $\mathrm{Al}_{2} \mathrm{O}_{3}$ content. On the other hand, the discrepancy in $\mathrm{Fe}_{2} \mathrm{O}_{3}$ and $\mathrm{CaO}$ content was justified by the sampling limitation: the liquefied soil was collected above the ground, thus exposing the sample to oxygen from atmosphere. The exposure induced the oxidation of $\mathrm{Fe}^{2+}$ to $\mathrm{Fe}^{3+}$ thereby producing a higher $\mathrm{Fe}_{2} \mathrm{O}_{3}$ content. Meanwhile, carbonate was dissolved, which reduced the $\mathrm{CaO}$ content. In addition to the similarity in mineral composition, the similarity in physical appearance (resemblance to silty clay) affirmed that the liquefied soil was liquefied loess, as further reflected by the comparable physical property (Table 1). 
Table 1

Mineral composition and physical property of liquefied soil and Malan loess

\begin{tabular}{|c|c|c|c|c|c|c|}
\hline \multirow[t]{2}{*}{ Soil sample } & \multicolumn{4}{|c|}{ Mineral composition (\%) } & \multicolumn{2}{|c|}{ Physical property } \\
\hline & $\mathrm{SiO}_{2}$ & $\mathrm{Al}_{2} \mathrm{O}_{3}$ & $\mathrm{Fe}_{2} \mathrm{O}_{3}$ & $\mathrm{CaO}$ & $\begin{array}{l}\text { Plasticity } \\
\text { index }\end{array}$ & $\begin{array}{l}\text { Clay content }(< \\
0.075 \mathrm{~mm})(\%)\end{array}$ \\
\hline Liquefied soil & 61.3 & 18.9 & 10.5 & 1.8 & 13 & 20.5 \\
\hline $\begin{array}{l}\text { Malan loess (adapted from Liu. } \\
\text { [insert citation] ) }\end{array}$ & $>60$ & & $3 \sim 6$ & $\begin{array}{l}7.5 \\
\tilde{10.5}\end{array}$ & $\begin{array}{l}7.6 \sim \\
15.7\end{array}$ & $7.0 \sim 30.4$ \\
\hline
\end{tabular}

Overall, based on visual inspection, micromorphology analysis, chemical composition analysis, and physical property comparison, the authors postulated that the observed rare liquefied soil was liquefied loess. It is important to emphasize that there has been no study reporting the discovery of liquefied loess in Northeast China. Unfortunately, due to time and financial constraint, neither drilling was performed at the site nor undisturbed soil sample was collected. Hence, further investigation is required to study the formation mechanism, factors governing the formation, and physical property of the postulated liquefied loess (e.g. natural density and moisture content).

\section{Conclusion}

Based on conducted post-earthquake field survey and subsequent analytical procedure (soil profile determination, CPT and SPT analysis, micromorphological study by SEM, and chemical composition analysis by XRD and XRF) at the epicenter of M5.7 Songyuan earthquake, the following conclusion was drawn:

1. Liquefaction was observed at the epicenter, and caused surface damage mainly to rice field.

Nonetheless, there was no large-scale damage to building. Due to the simple profile of regional soil layer, the distribution of liquefaction was primarily governed by ground motion, landform, and groundwater level.

2. Deep liquefaction. Most liquefaction was identified at shallow depth: at soil layer with the depth less than $10 \mathrm{~m}$. The liquefaction produced surface damage and was easily discernable by the phenomena such as sand boil and water spout. On the other hand, deep liquefaction is commonly neglected in field investigation. Nonetheless, in this paper the authors reported the upward movement of liquefied sand from the lower sand layer towards the upper clay layer located at the depth between 16 and $17 \mathrm{~m}$, suggesting the occurrence of deep liquefaction at the depth of between 18 and $19 \mathrm{~m}$. This phenomenon is rarely reported by other field investigation. Additionally, the accuracy of existing method to determine the occurrence of deep liquefaction is low, hence requiring further improvement.

3. On-site determination method of liquefaction. This study reported the occurrence of liquefaction at the sites with no apparent surface macrophenomena (e.g. sand boil and water spout). Unfortunately, existing 
field investigation method (drilling and SPT) are not practical for identifying such liquefaction occurrence. Hence, alternative method which is more efficient and accurate is necessitated. CPT is a candidate for the alternative method. It requires less time and produces more accurate result than the current drilling and SPT method. Moreover, it is applicable on-site during post-earthquake investigation for identifying sand liquefaction. Nevertheless, given the recent incorporation of the method into on-site post-earthquake investigation, more field data are required to improve the reliability of the method.

4. Rare soil liquefaction. In addition to the typical sand liquefaction, rare soil liquefaction, specifically loess liquefaction, was postulated. This study is the first study which reported the occurrence of loess liquefaction at Northeast China. Nonetheless, further investigation is required to understand the formation mechanism and factors controlling the formation and/or distribution of the loess liquefaction.

5. High risk of liquefaction at Songyuan. Songyuan is one of the only two cities in Northeast China which is fortified against seismic intensity of VIII. The local seismic activity is frequent and characterized by multiple earthquake swarm. The soil layer is constituted by thick loose sand and the groundwater is located at a shallow depth. Overall finding of this study suggests a high risk of liquefaction at Songyuan, contributed by not only typical sand liquefaction but also rare soil liquefaction such as the postulated loess liquefaction. Therefore, research dedicated to studying the liquefaction at Songyuan is essential for improving planning on earthquake mitigation and design project.

\section{Declarations}

\section{Acknowledgment}

This work is partly funded by Scientific Research Fund of Institute of Engineering Mechanics, China Earthquake Administration(Grant No. 2020EEEVL0303)and Spark project of seismic science and technology $\square$ Grant No. XH20084区. The authors would like to thank the Songyuan earthquake agency for the support during post-earthquake investigation. Similarly, the authors are grateful to China Strong Motion Network Centre at Institute of Engineering Mechanics, China Earthquake Administration, for contributing to the data of this study.

\section{References}

[1] Yuxian H. Earthquake engineering. Beijing Seismological Press; 1988 (in Chinese)

[2] Institute of Engineering Mechanics. Haicheng earthquake damages. Beijing Seismological Press; 1979 (in Chinese)

[3] Huixian L. Damage in Tangshan Great Earthquake. Beijing Seismological Press; 1989 (in Chinese)

[4] Jingshan B, Liping J. On the problems of soil dynamics related to seismic micro-zonation. Global Geology 1997; 16(2): 66-71 (in Chinese) 
[5] Zhenzhong C, Xiaoming Y, Longwei C, et al. Summary of liquefaction macrophenomena in Wenchuan Earthquake. Chinese Journal of Geotechnical Engineering 2010; 32(4): 645-650 (in Chinese)

[6] Liang W, Jingshan B, Xiaobo L, et al. Research progress on methods of sand liquefaction potential evaluation. World Earthquake Engineering 2017; 33 (4): 141-150 (in Chinese)

[7] Sonmez B, Ulusay R, Sonmez H. A study on the identification of liquefaction-induced failures on ground surface based on the data from the 1999 Kocaeli and Chi-Chi earthquakes. Engineering Geology 2008; (97): 112-125

[8] Ge W, Heyan F, Zhitian L囚et al. The investigation and research of Qianguo earthquake in 1119. Seismological Research of Northeast China 1988; (1): $69-78$ (in Chinese)

[9] Wen Y, Yan X, Xiaotao Z, et al. Study of seismic sequence characteristics of Songyuan 4.9 earthquake in 2017 and Songyuan 5.7 earthquake in 2018. Recent Development in World Seismology 2018; 8: 77 (in Chinese)

[10] Meixuan W, Ximin H, Han L, et al. Sand liquefaction disaster research of 2013 M5.8 Qianguo earthquake swarm based on GIS. Journal of Disaster Prevention and Reduction 2016; 32 (3): 64-69 (in Chinese)

[11] Onder CK,.Seed RB, Robert EK, et al. Examination of differences between three SPT-based seismic soil liquefaction triggering relationships. Soil Dynamics and Earthquake Engineering 2018; 113: 75-86

[12] Lalita GO , Mandar D, Scott MO. Comparing laboratory liquefaction resistance of a sand with nonplastic fines with shear wave velocity-based field case histories. Soil Dynamics and Earthquake Engineering 2018;113: 162-173

[13] Richard SO. Liquefaction analysis using the cone penetrometer test. Civil Engineering Vicksburg Mississippi, USA: 247-254

[14] Zhaoyan L, Xiaoming Y, Zhenzhong $C$, et al. New evaluation formula for sand liquefaction based on survey of Bachu earthquake in Xinjiang. Chinese Journal of Geotechnical Engineering 2012; 34 (3): 483489 (in Chinese)

[15] Zhaoyan L, Rui S, Zhenzhong C, et al. Feasibility of cone penetration test to evaluating Bachu earthquake liquefaction. Rock and Soil Mechanics 2010; 31(12): 3907-3912 (in Chinese)

[16] Wei L. Study on the liquefaction characteristics of $\mathrm{Q}_{3}$ loess under pre-dynamic loading [Ph.D.Dissertation]. University of Lanzhou; 2019

\section{Figures}




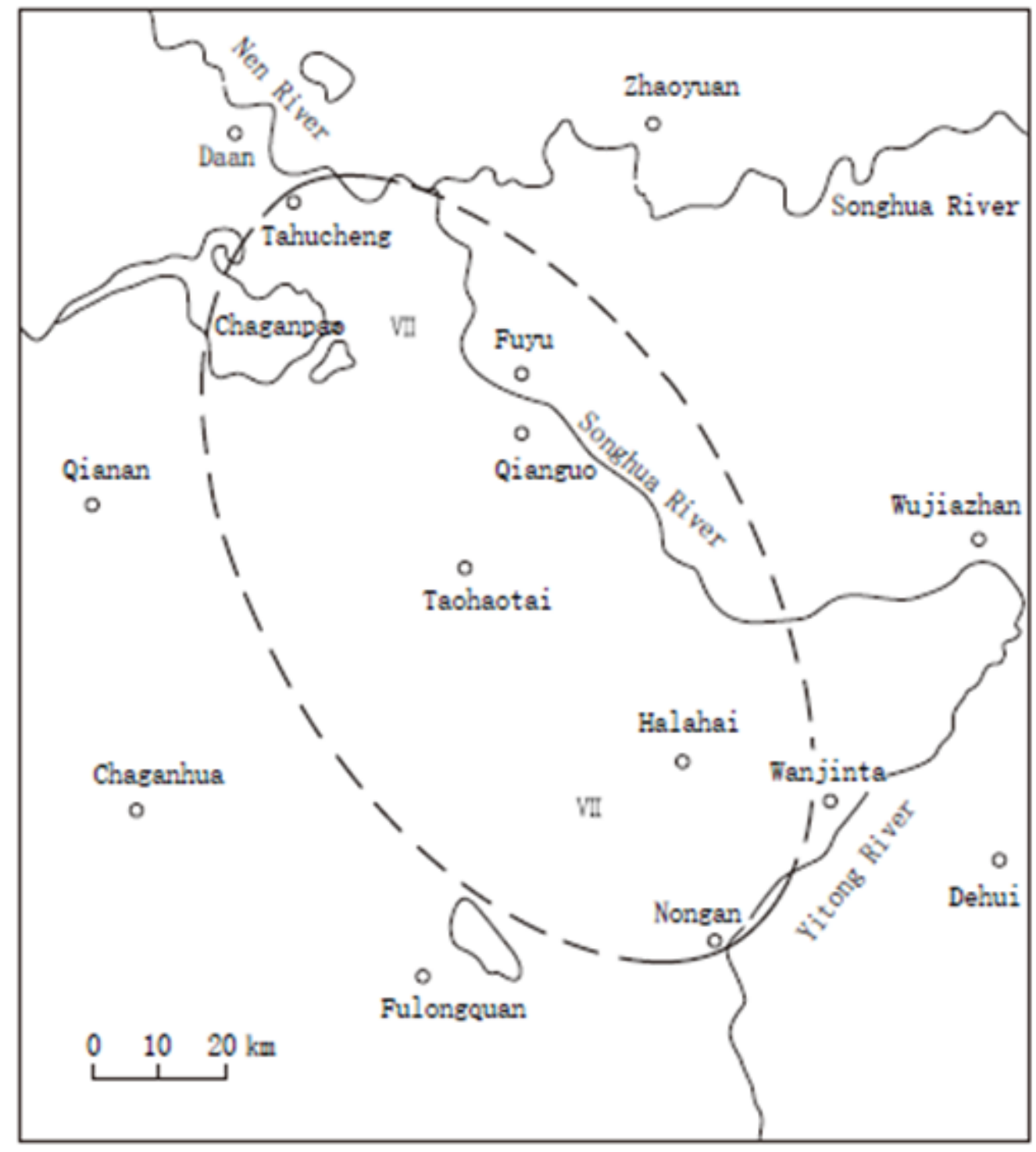

Figure 1

Isoseismal map of Qianguo earthquake occurring on 1119 at the surrounding region of Songyuan city. Adapted from $\mathrm{Ge}$ et al. [8]
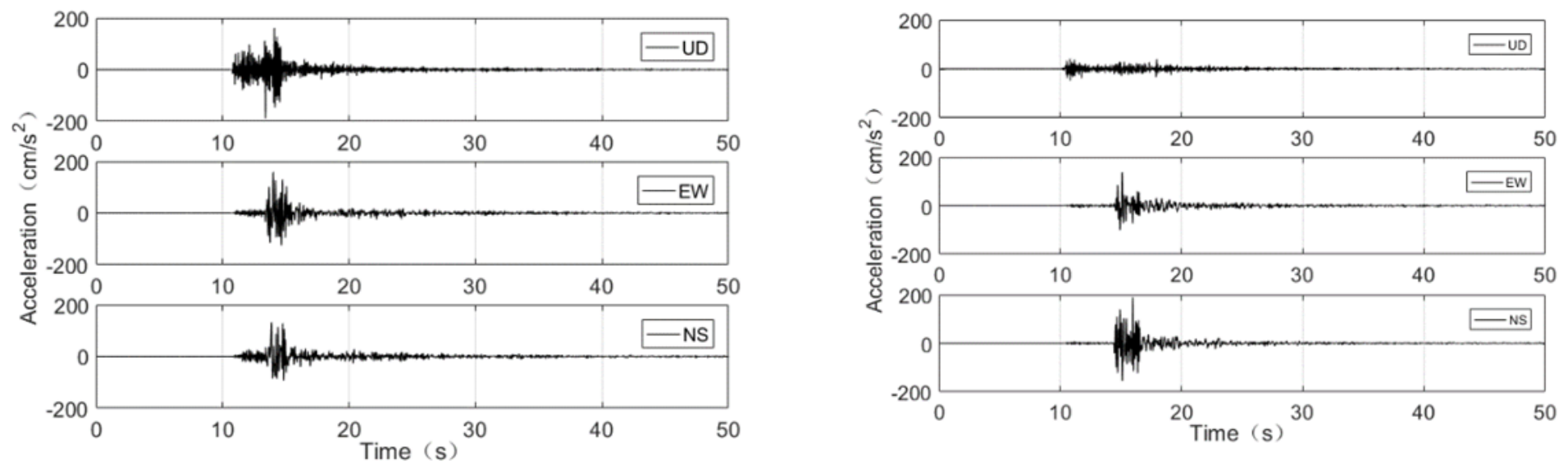

Figure 2 
Strong motion record documented at Daliba and Fenghua station
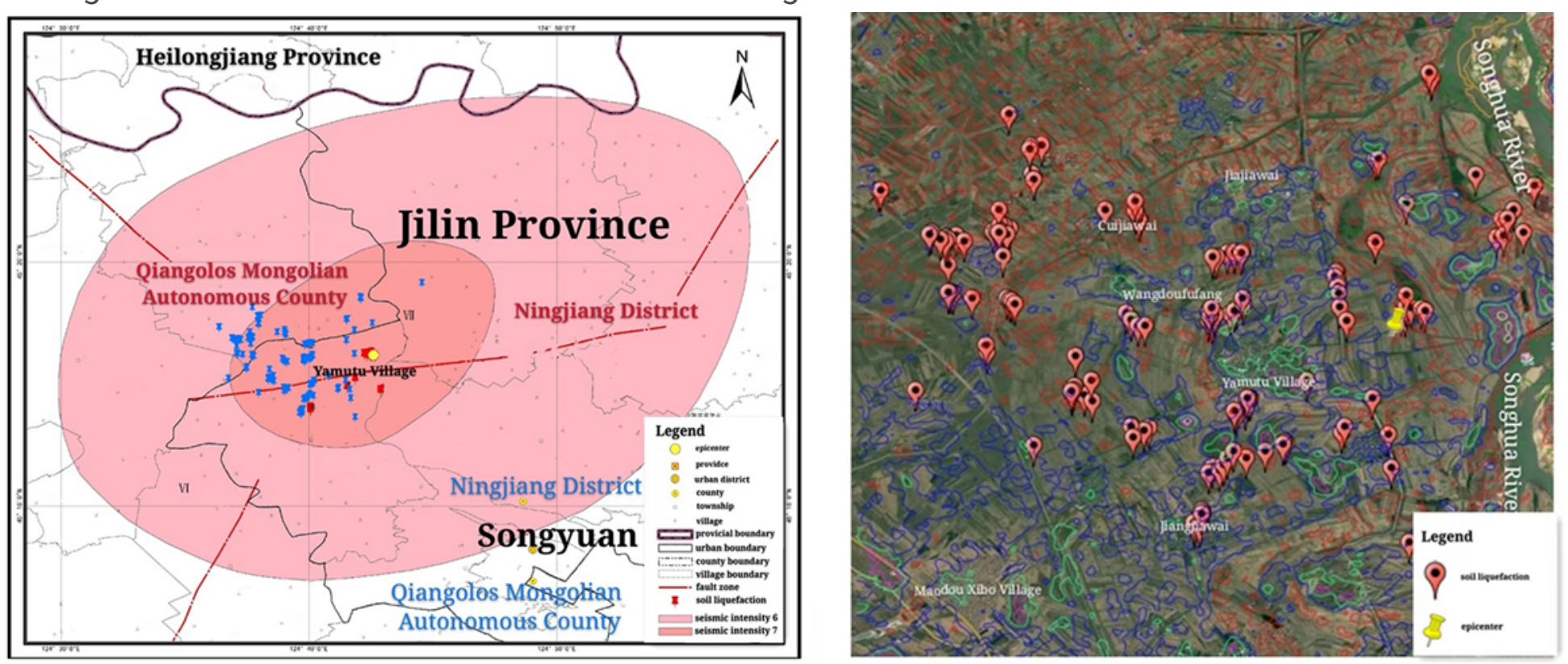

\section{Figure 3}

Distribution of liquefaction induced by Songyuan earthquake

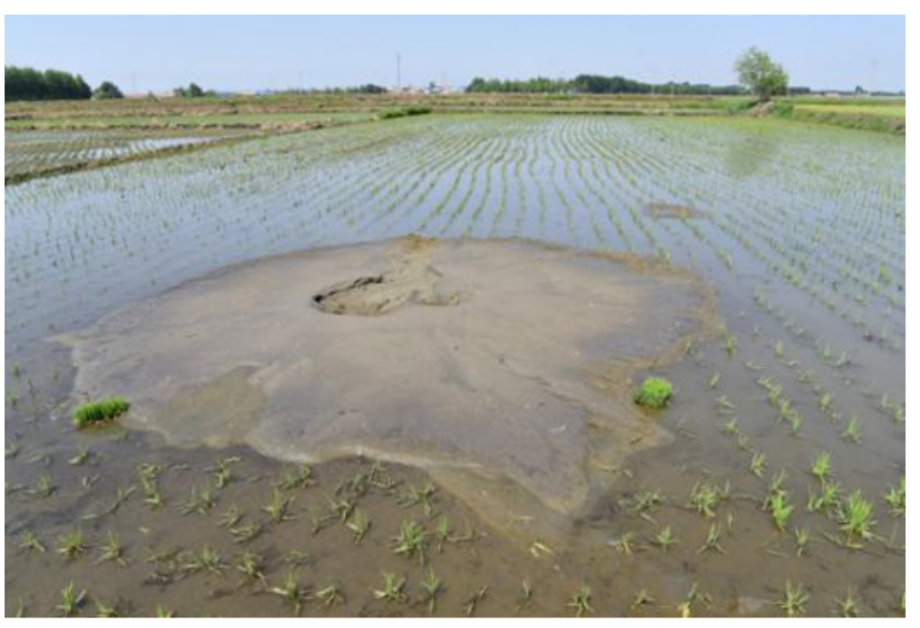

(a)

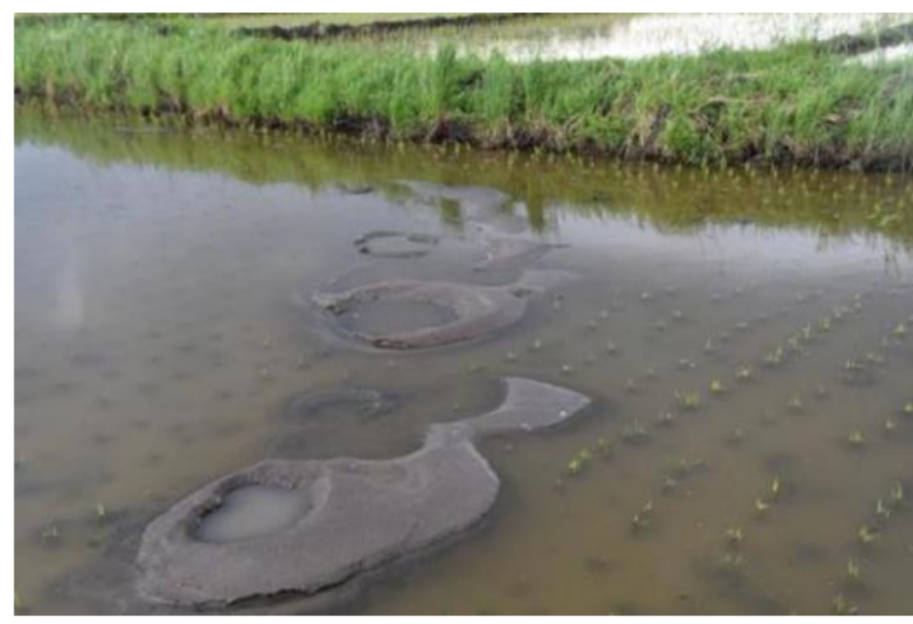

(b)

\section{Figure 4}

Typical macrophenomena observed on liquefaction sites (a) Concentric-shaped eruption with a direction of $28^{\circ}$ and (b) string beads-shaped eruption at a direction of $354^{\circ}$ 


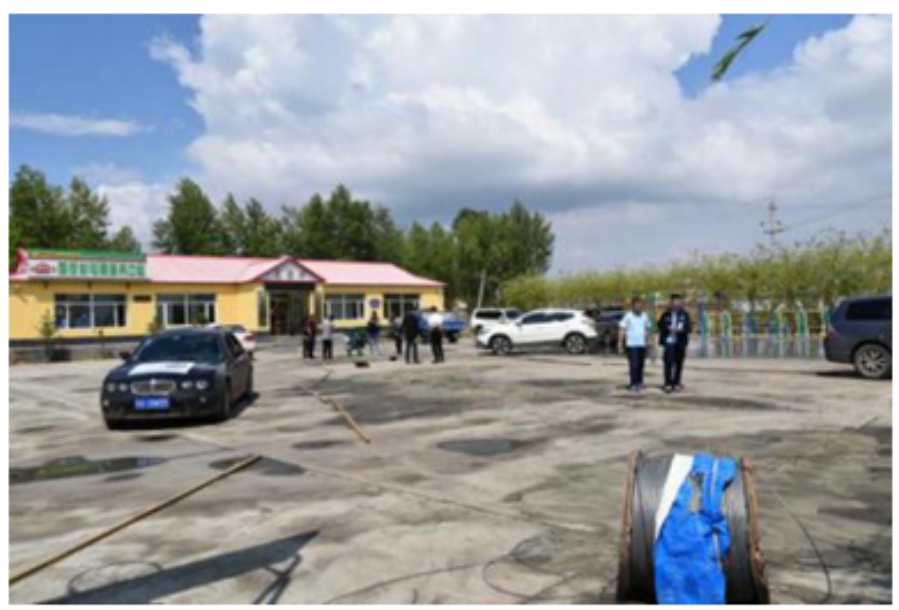

(a)

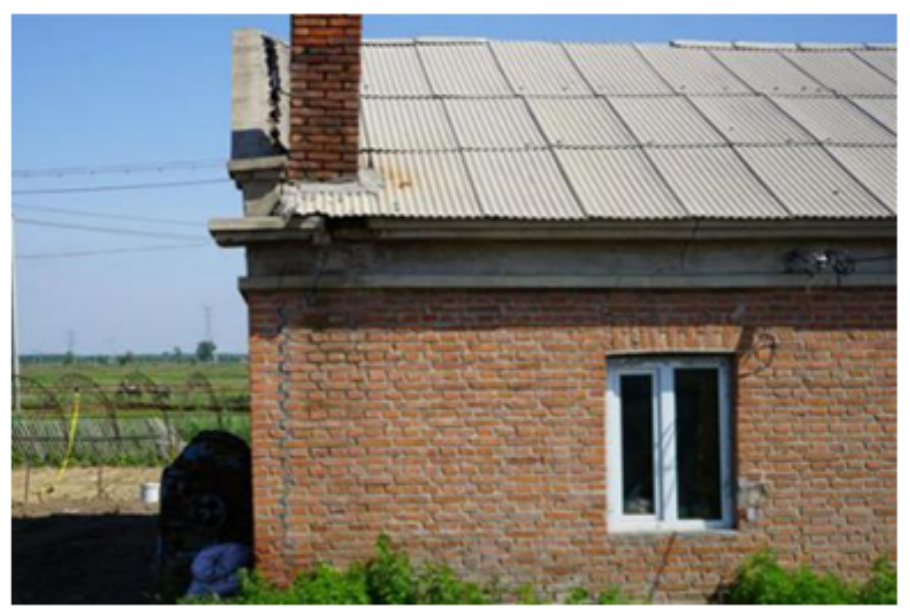

(c)

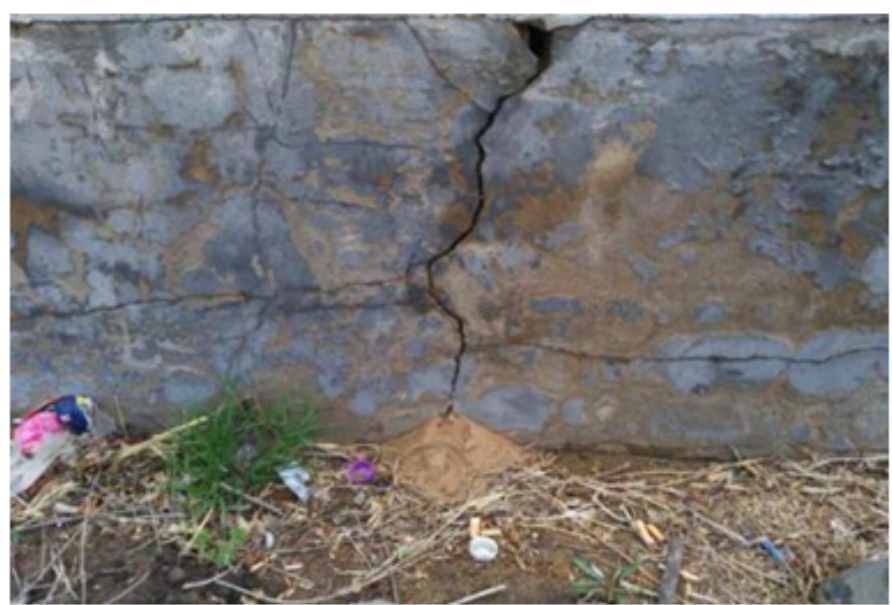

(b)

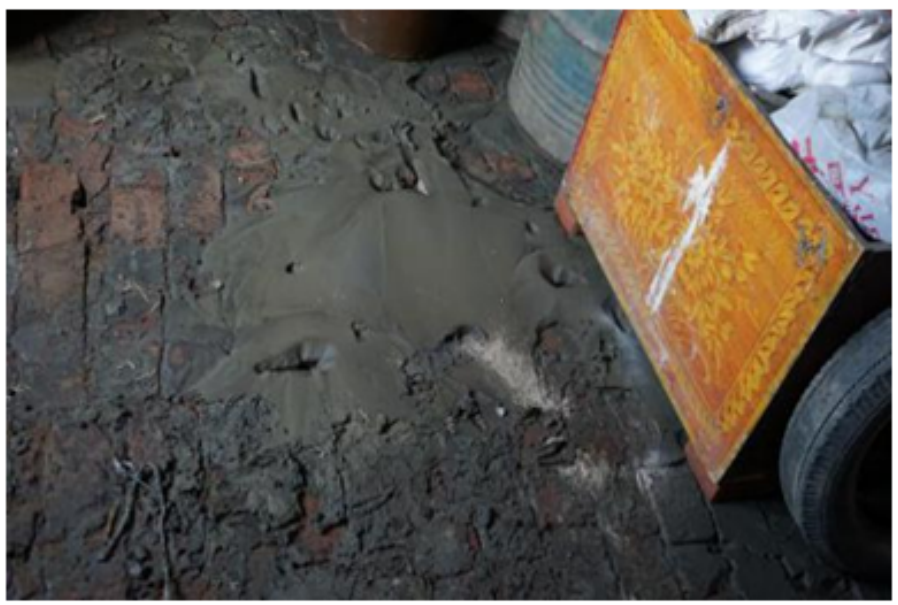

(d)

\section{Figure 5}

Construction damage due to liquefication: damage to a village committee office at Jiangjia ( $a$ and $b)$ and damage to a house in Cuijia ( $c$ and $d$ ) 


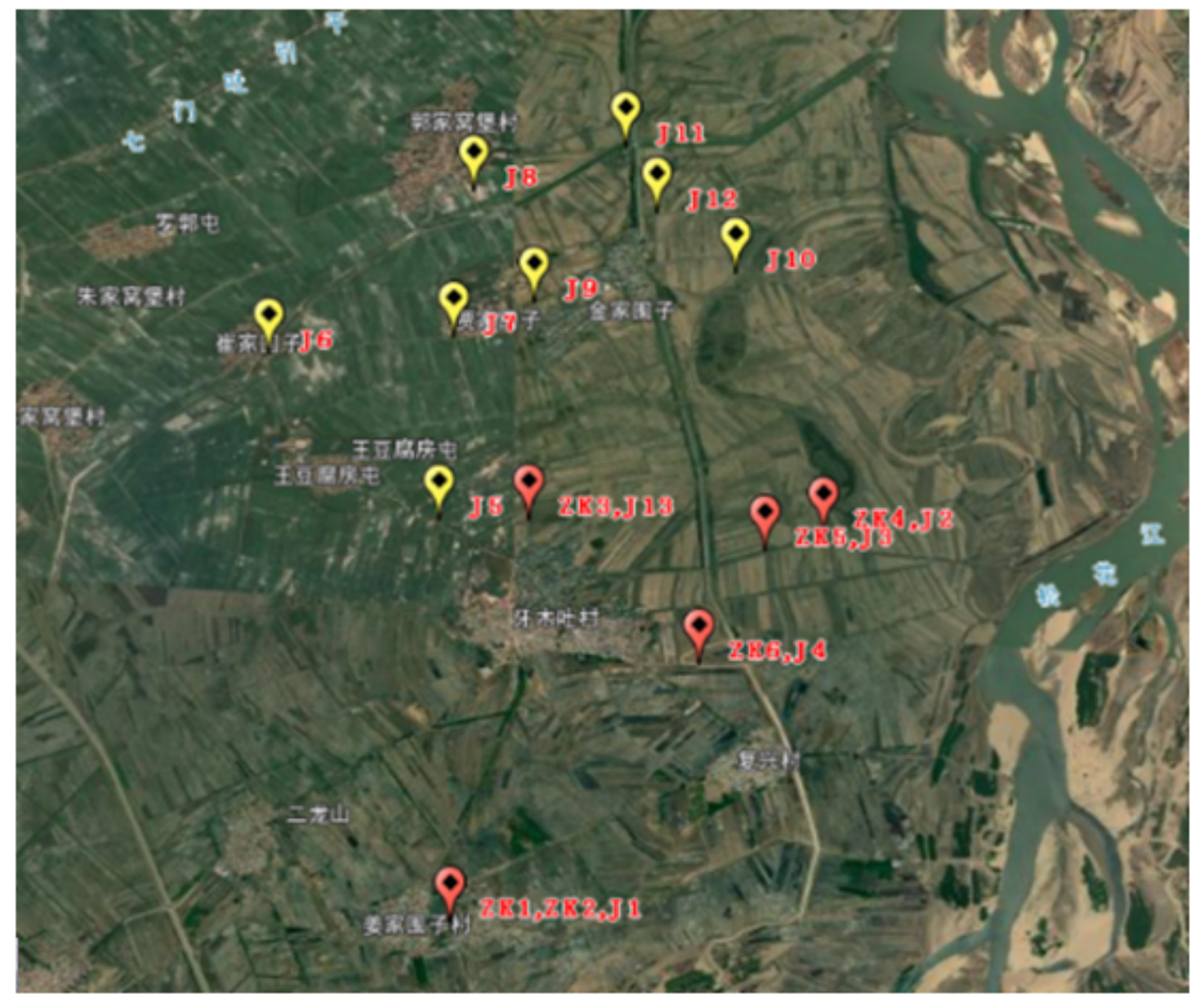

\section{Figure 6}

Sites at which drilling and cone penetration test were performed during field survey. ZK and $\mathrm{J}$ indicate the sites at which drilling and CPT were conducted respectively

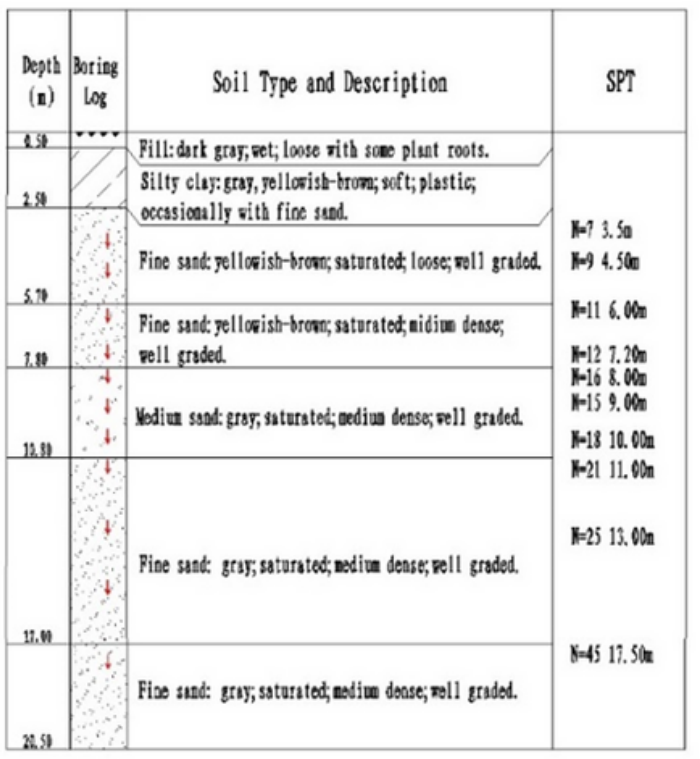

(a)

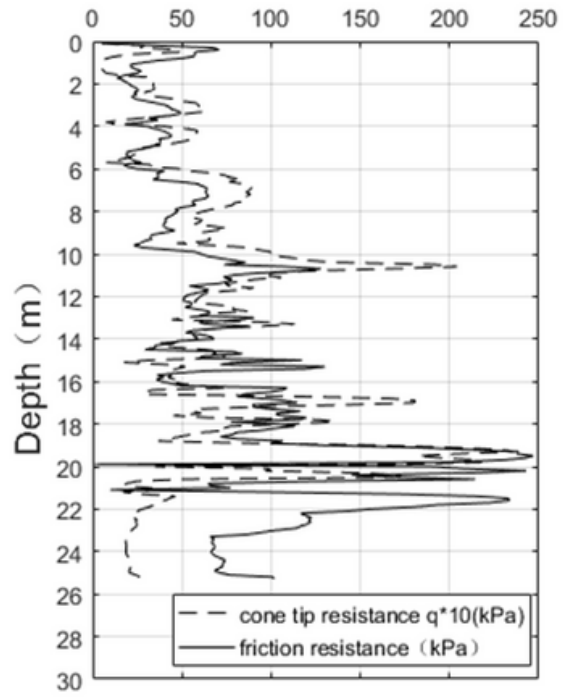

(b)

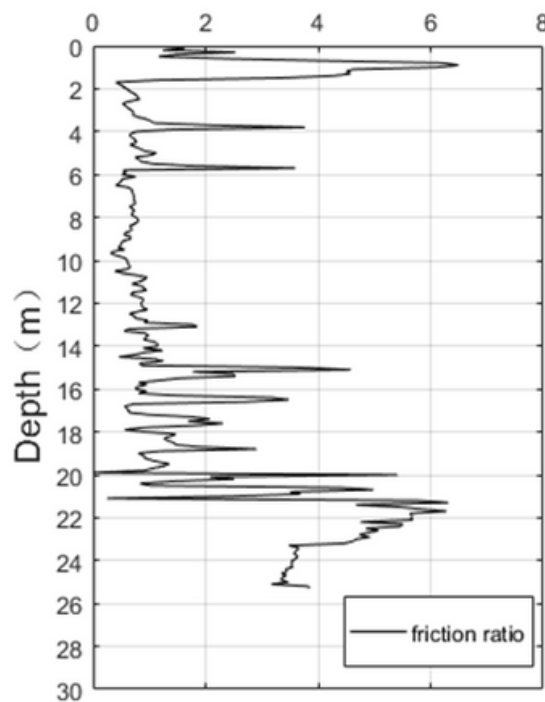

(c)

Figure 7 
Soil profile (a), standard penetration test analysis (b), and cone penetration test analysis (c) of soil collected at liquefaction site

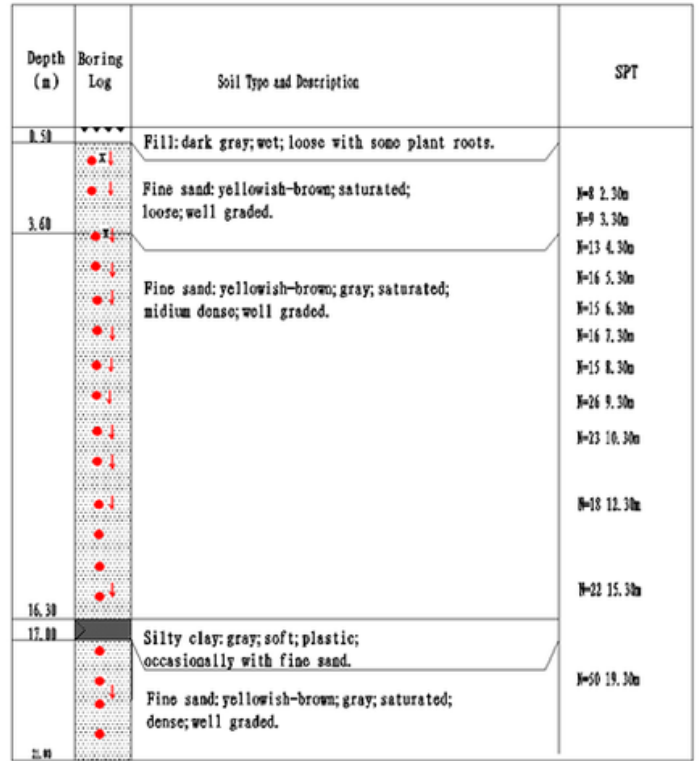

(a)

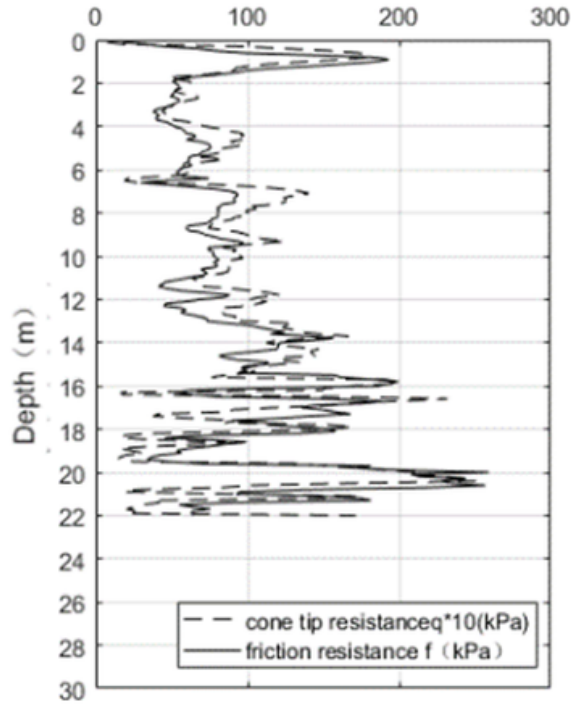

(b)

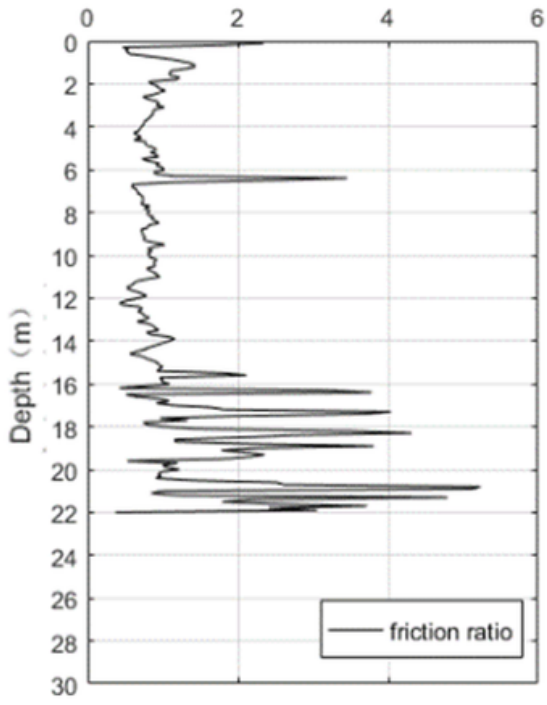

(c)

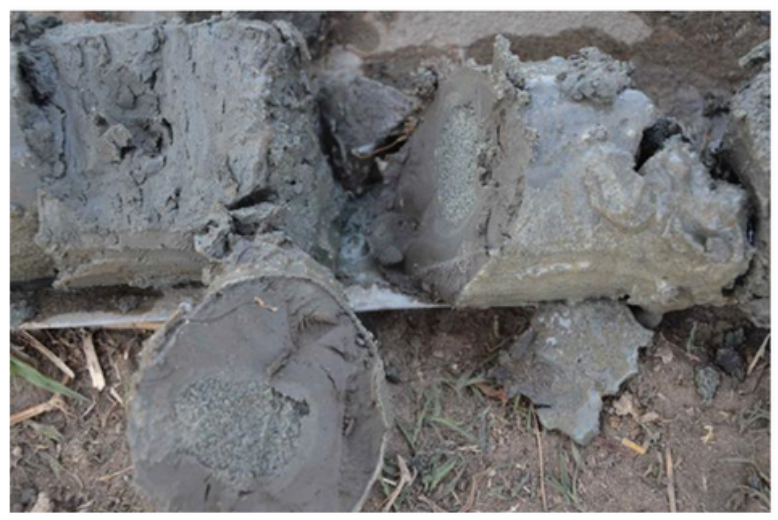

(d)

Figure 8

Soil profile (a), standard penetration test analysis (b), and cone penetration test analysis (c) of soil collected at non-liquefaction site. In addition, deep layer liquefaction (d) was observed at the site. 


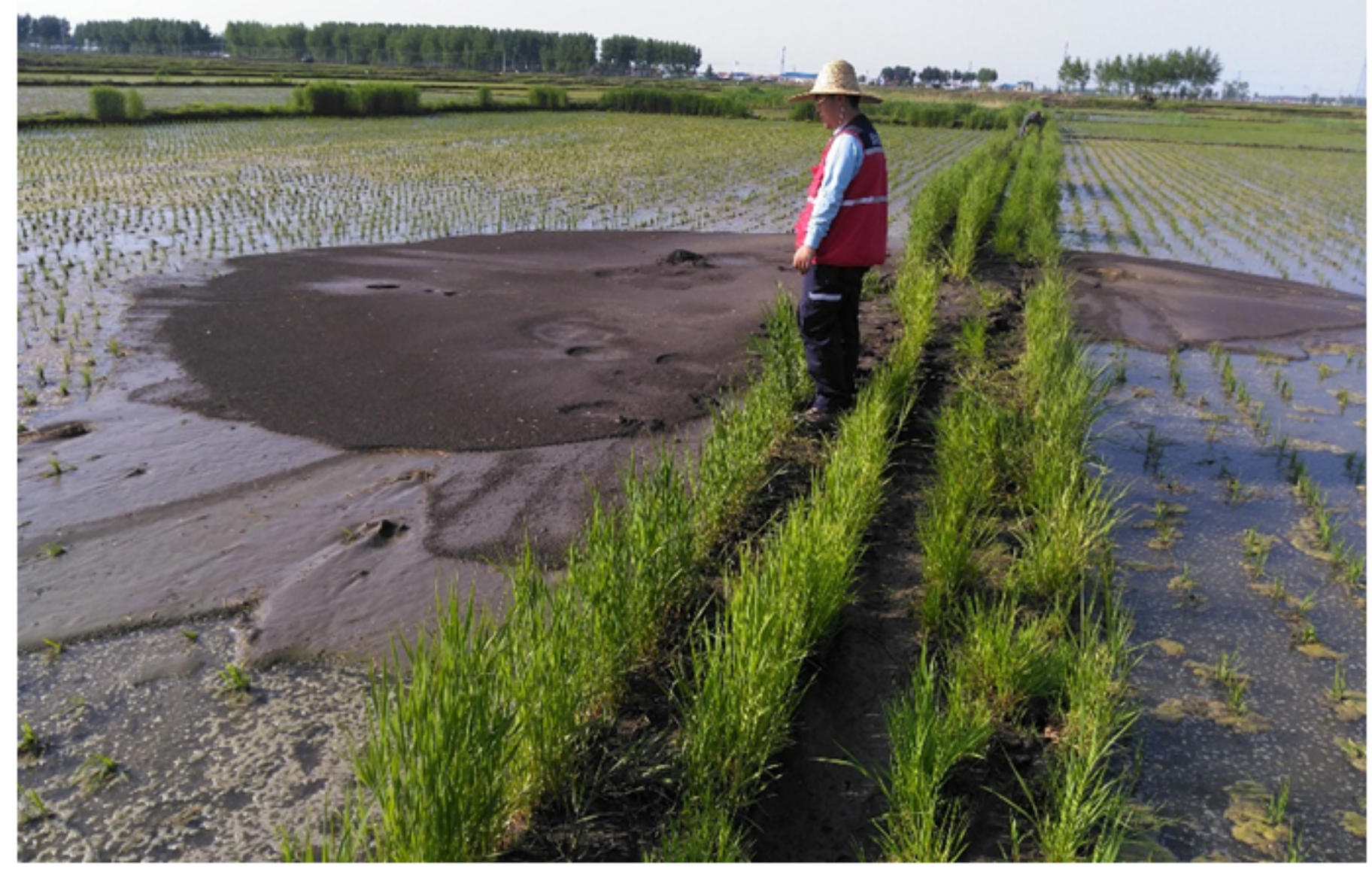

Figure 9

Rare soil liquefaction discovered on a rice field at Wangjia Village


\section{Figure 10}

Scanning electron microscope image of liquefied soil at increasing magnification: (a) 200x, (b) 800x , and (c) $2000 x$ 


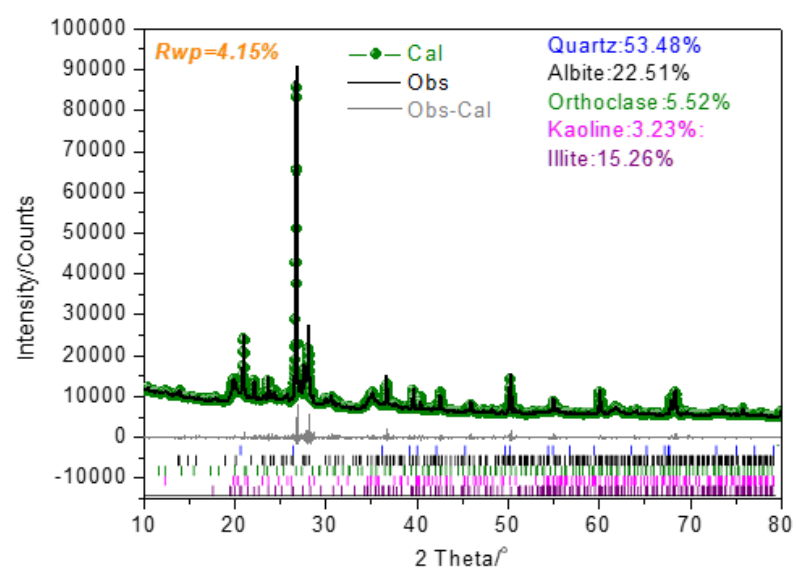

(a)

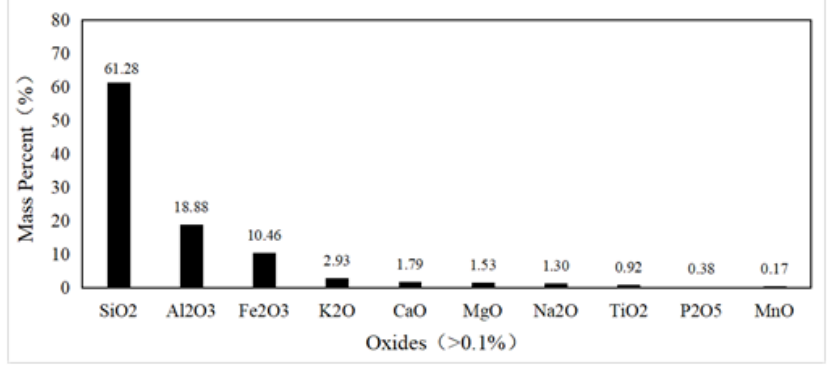

(b)

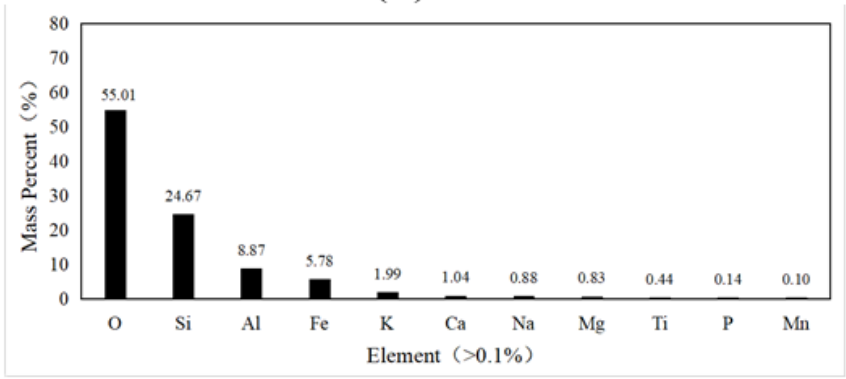

(c)

\section{Figure 11}

Mineral (a), elemental oxide (b), and element (c) composition of liquefied soil 